The Geographical Journal of Nepal

Vol. 14: 1-20, 2021

DOI: https://doi.org/10.3126/gjn.v14i0.35544

Central Department of Geography,

Tribhuvan University, Kathmandu, Nepal

\title{
Assessment of urban heat island in Kathmandu valley (1999-2017)
}

\author{
Dipendra Salami Magar', Ramesh Kumar Salami Magar¹, Chhabi Lal Chidi ${ }^{*}$ \\ ${ }^{1}$ Central Department of Geography, Tribhuvan University, Kathmandu \\ *Corresponding author: chidichhabilal@gmail.com
}

Received: 03 October, 2020; Accepted: 28 October, 2020; Published: March 2021

\begin{abstract}
Growing urbanization results built up surfaces converting from agriculture land, forest and other natural land cover surfaces. Increasing built up surfaces, means of transport and industrial activities are major results for increasing temperature in the city area as compared to other areas. Increasing heat is a concern to human health of the people living in urban areas. Increasing temperature in the city area in developing countries is being a growing concern. Kathmandu Valley is one of the most rapidly growing urbanized region in Nepal. The present study aims to assess the changing Land Surface Temperature (LST) in Kathmandu valley using LANDSAT 7 images. Similarly, Urban Heat Island (UHI) effect was evaluated in land use categories which were derived from Google Earth images. Study revealed that built up area contributed highly to increase land surface temperature. New built up with compact settlement area has higher land surface temperature as compare to other land use/land cover surfaces. City core has higher LST as compared to less urbanized and surrounding parts. The LST has highly increased during 1999 to 2017 with increasing urbanization. However, the ecological condition of UHI effect is not so bad till date but the study result indicated the continuous increasing urbanization may result worse ecological condition in Kathmandu Valley in the future.
\end{abstract}

Keywords: Ecological condition; land surface temperature; urban heat island, urbanization

\section{Introduction}

Most of the large cities in the world have higher temperature at the center of the city as compared to its surrounding areas is known as Urban Heat Island (UHI) (Adinna et al., 2009; Nuruzzaman, 2015). Dense built-up areas, concrete zones and high concentration 
of anthropogenic activities lead to the development of urban micro-climates which is associated to generate UHI. Extensive urbanization transforms the land use/land cover (LULC) modifying the energy balance, which makes cities warmer than their hinterland and surroundings. Urban growth is characterized by the transformation of natural land use/land cover into artificial human induced built up surfaces and concentration of population activities. These transformations cause the depletion the proportion of greenery and subsequent increase of impervious surface and causes structural shift of employment from primary to tertiary activities. Increasing industrialization and transport activities add to greenhouse gases in the atmosphere and they also absorb the outgoing terrestrial long wave radiation and contribute to increase temperature in the city. Thus, the city center is heated up leading to the creation of UHI (Grover and Singh, 2015). Thus, growing urbanization has adverse effect on land surface properties with their thermal capacity. Increasing potential thermal storage creates UHI effect in the city center and its effect decreases to outer side (Stewart and Oke, 2012). As UHI emerges, through the modification of land surface characteristics in favor of heat storage, heat trapping and anthropogenic heat release which is being a growing concern of environmental risk (Grimmond, 2007; Li et al., 2020). Growing heat degrades air quality influencing local climate and increase ground level ozone production, which effects on quality of life (Lo and Quattrochi, 2003). Urban population is growing in the world and more than half of the total populations live in urban area and its increasing rate will continue until 2050 (Leeson, 2018; United Nations, 2014). At present, ninety percent increase of world urban population is in the developing countries. There are rapid changes in the urban environment as a result of urban growth among which urban climate particularly rapid increase in temperature under the city area creating UHI as compared to its surrounding areas (Alfraihat, et al., 2016). The UHI affects urban quality of life through the impact on human health, ecosystem function and local weather and climate (Wienert and Kuttler, 2005). Therefore, the issue of UHI is being a crucial issue in various disciplines whether they are natural or social sciences because of the multiple implications on climatic system and human welfare (Gao et al., 2019). Remote sensing technology has made possible to monitoring UHI creation of urban areas more efficiently and cost effective due to freely available thermal images (Jeevalakshami et al., 2017) and its application is growing with urbanization process in the world.

Nepal is a developing country where the urbanization process is very fast. In the last few decades, Kathmandu valley is the largest and fastest growing city. Some studies have revealed the factors causing the creation of UHI in Kathmandu city. Nepal is mountainous country and Kathmandu valley is in the middle hill having high elevation differences with an effect on lapse rate of temperature but past studies has neglected this aspect. The main city area lies in the low altitude valley floor surrounded by higher 
hill. Lapse rate is the decreasing temperature with increasing altitude (Kattel et al., 2013). Thus, temperature generally decreases in the surrounding areas of foot hills and hill slope as compared to lowland city area. Thus, it should be clear that the increasing temperature in the valley floor (city area) is due to the effect of lapse rate because of elevation change or due to the urbanization. Therefore, there is urgent need of studies to identify and address the change by lapse rate and/or heat created by urbanization. In this context, the present study aimed to assess the real situation of UHI in Kathmandu valley due to urbanization process during 1999 to 2017.

\section{The study area}

The total area of Kathmandu valley is $670 \mathrm{~km}^{2}$. The geographical extension is $27^{\circ} 32^{\prime} 13^{\prime \prime} \mathrm{N}$ to $27^{\circ} 49^{\prime} 10^{\prime \prime} \mathrm{N}$ latitude and $85^{\circ} 11^{\prime} 31^{\prime \prime} \mathrm{E}$ to $85^{\circ} 31^{\prime} 38^{\prime \prime} \mathrm{E}$ longitude. This valley includes whole area of Kathmandu and Bhaktapur districts and northern part of Lalitpur district. The elevation ranges from $1095 \mathrm{~m}$ to $2785 \mathrm{~m}$ from the average mean sea level. The average elevation of valley plain is $1300 \mathrm{~m}$.

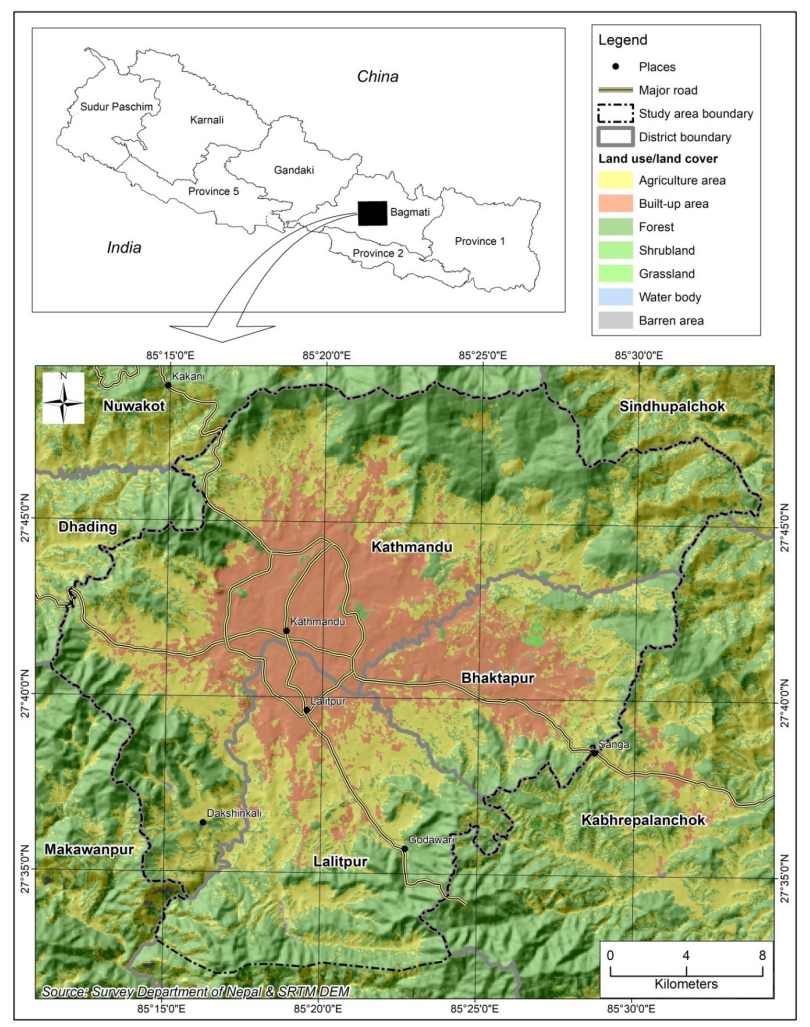

Figure 1: The study area (Kathmandu Valley) 
Kathmandu valley is surrounded by high hills composed of schist, gneiss and granitic rock in the north and slightly metamorphosed sedimentary rocks in the south, east and west. Lacustrine soil is common in the lowland areas of the valley because this valley was developed due to the drying up of a lake. Sandy and red soils are prevalent in the hillsides. Most part of the valley is under the warm temperate climatic region and some higher surrounding hills are under cool temperate. Average temperature ranges from $3^{\circ} \mathrm{c}$ in winter to $30^{\circ} \mathrm{c}$ in summer hot season. The average rainfall is $1500 \mathrm{~mm}$ in which $80 \%$ of them fall in summer monsoon season (DHM, 2015).

Kathmandu is the largest city and the capital city of Nepal. Most of the central level government headquarters, and commercial centers of the country are located in the valley. It has different heritage sites. Kathmandu valley occupies less than one percent of the total area of the country but it has $31 \%$ urban population of Nepal. Urban growth of valley accelerated since 1980 and growth rate was quite high during 1990 decade (Subedi, 2014). The annual growth rate of population in Kathmandu valley was $4.34 \%$ and 4.87 during 1991 to 2001 and 2001 to 2011 respectively. The built-up area was $5.1 \%$ in Kathmandu Valley in 1989 and reached 26.06\% in 2016 (Ishtiaque et al., 2017), which is quite higher than four times increase built-up area during this period.

\section{Methods and materials}

Methodology consists of two major steps to fulfill the objectives of the study. One is land use/land cover area extraction and another is computation of LST and UHI. Land use and land cover data was derived by digitized from Google Earth image. LST was derived from satellite image and UHI was derived from LST data. Finally, spatial variability of LST and UHI were analyzed to derive conclusion. The concise process flow of methods has been given in figure 2 .

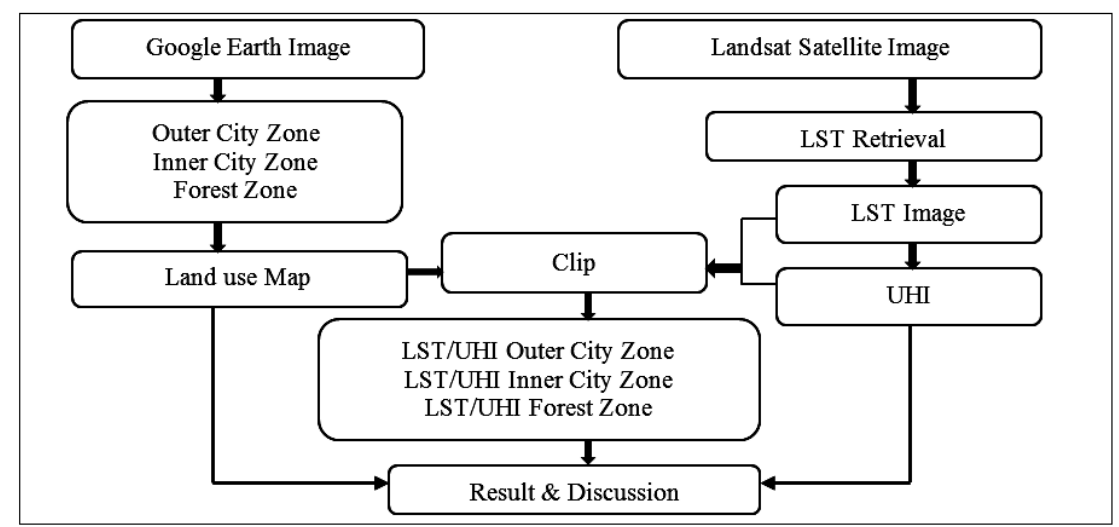

Figure 2: Workflow of the study 


\section{Data source}

Topographic map, remote sensing image and Google Earth images were major data sources of the study. Topographic map of scale 1:25000 of Kathmandu valley was collected from Survey Department of Nepal, which was used to derive boundary of Kathmandu valley. Google earth image was used to derive land use data, identify the location and area for field observation. SRTM Digital Elevation Model (DEM) data of $90 \mathrm{~m}$ spatial resolution that are freely available in website http://srtm.csi.cgiar.org/ srtmdata was used to calculate altitude of land surface where land surface temperatures were calculated. LANDSAT 7 images of 1999 and 2017 are freely available in website https://earthexplorer.usgs.gov. These data were processed by NASA to generate radiometric and atmospheric correction algorithms to the Level 1 products. The further description of LANDSAT 7 data has been given in Table 1.

Table 1: Description of LANDSAT image

\begin{tabular}{|c|c|c|c|c|}
\hline Image name & Acquired date & Time & Path/Row & Projection \\
\hline Landsat7 & $1999 / 11 / 04$ & $04: 41: 12$ & $141 / 041$ & WGS 84UTM ZONE45 \\
\hline Landsat7 & $2017 / 11 / 21$ & $04: 50: 54$ & $141 / 041$ & WGS 84UTM ZONE45 \\
\hline
\end{tabular}

Several published and unpublished documents were collected from different available sources. Those were PhD Dissertations, Master theses, reports, books, and various national and international journals related to the urban heat island. Similarly, various documents of heat stress, heat mitigation, report of ADB/ICIMOD and published by different organization.

\section{Data processing}

Land use/land cover data preparation, calculating land surface temperature and identifying ecological condition through Urban Heat Island are the data processing steps of the study.

\section{Land use/land cover data}

Land use/ land cover maps were derived from the Google earth image of 1999 and 2017. Land use/land cover features were categorized into three classes. Compact urban built-up areas were categorized into Inner City Zone, surrounding cultivated area with dispersed and agglomerated settlement were categorized into Outer City Zone and remaining forest, shrub and grass covered areas including sparsely distributed cultivated lands were categorized into Forest Zone. Identification of these three zonal boundaries 
was based on prior knowledge of local reality of Kathmandu valley. Average altitudes of three zones were derived by SRTM DEM of 90m spatial resolution.

\section{LST calculation}

Land surface temperature (LST) is a key parameter in the physics of the earth surface through the process of energy and water exchange with the atmosphere, which plays an important role in a wide variety of scientific studies, such as ecology, hydrology, and global change studies (Liang et al., 2012; Zhang and He, 2013). In the present day, advancement of satellite data has widely used in environmental related studies and climate change. Thermal bands (band 6) of LANDSAT 7 images of November were used to calculate the land surface temperature (Suresh et al., 2016). Similarly, metadata of corresponding images were used for the calculation of LST. An equation is used to calculate land surface temperature using information given by thermal sensor of satellite and it is used by several scientists (Artis and Carnahan, 1982; Das, 2015; S.V. and K., 2016) is given below:

$\mathrm{LST}=\mathrm{BT} /\left\{1+w^{*}(B T / p)^{*} L_{n}(e)\right\}$

where,

LST $=$ Land surface temperature

$\mathrm{BT}=$ At satellite temperature

$\mathrm{W}=$ Wavelength of emitted radiance $(11.5 \mu \mathrm{m})$

$\mathrm{p}=\mathrm{h} * \mathrm{C} / \mathrm{S}\left(1.438 * 10_{\Lambda}-2 \mathrm{mk}\right)$

$\mathrm{h}=$ Planck's Constant $(6.626 * 10 \Lambda-34 \mathrm{JS})$

$\mathrm{s}=$ Boltzmann Constant $(1.38 * 10 \Lambda-23 \mathrm{~J} / \mathrm{K})$

$\mathrm{C}=$ Velocity of light $(2.998 * 10 \Lambda 8 \mathrm{~m} / \mathrm{s})$

$\mathrm{p}=1.4380$

To find the satellite temperature, TIRS data can also be converted from spectral radiance to brightness temperature, which is effective temperature reviewed by the satellite under an assumption of unit emissivity. The conversion formula is follows (USGS, 2015):

where,

$$
\mathrm{T}=\frac{K_{2}}{L_{n}\left(\frac{K_{1}}{L_{\lambda}}+1\right)}
$$


$\mathrm{T}=$ top of atmospheric brightness temperature in Kelvin

$L_{\lambda}=$ Spectral radiance $\left(\right.$ watts $\left./ \mathrm{m}^{2} * \mathrm{~s}{ }^{*} \mu \mathrm{m}\right)$

$\mathrm{K}_{1}=$ Thermal conversion constant for the band

$\mathrm{K}_{2}=$ Thermal conversion constant for the band

Here, the output is in Kelvin unit of top of atmospheric brightness temperature which can be converted into degree centigrade by subtracting 272.15 (Das, 2015; S.V. and K., 2016). It is satellite temperature. Spectral radiance ( $L_{\lambda}$ is calculated using digital number (DN) of TIRS data using the formula given below (USGS, 2015):

$L_{\lambda}=M_{L}^{*} Q_{\text {cal }}+A_{1}$

where,

$L_{\lambda}=$ spectral radiance

$\mathrm{M}_{\mathrm{L}}=$ Radiance multiplicative scaling factor for the band

$\mathrm{A}_{1}=$ Radiance additive scaling factor for the band

$\mathrm{Q}_{\text {cal }}=$ Level 1-pixel value in DN

Emissivity (e) is calculated using the following equation (Carlson and Ripley, 1997).

$\mathrm{e}=0.004 * \mathrm{Pv}+0.986$

Where,

$\mathrm{e}=$ emissivity and

$\mathrm{Pv}=$ Proportion of vegetation

Proportion of vegetation $(\mathrm{Pv})$ is calculated using the following formula:

$\mathrm{PV}=\frac{N D V I-N D V I_{\min }}{N D V I_{\max }-N D V I_{\min }}$

Whereas, NDVI is calculated using the following formula (Lillesand et al., 2008):

$\mathrm{NDVI}=\frac{N I R-\operatorname{Re} d}{N I R+\operatorname{Re} d}$

\section{LST validation}


As calculated LST of November in both years of 1999 and 2017, the lapse rate of temperature in Nepal is $5.3^{\circ} \mathrm{c} / 1000 \mathrm{~m}$ altitude (Kattel et al., 2012) which means $5.3^{\circ} \mathrm{c}$ temperature decreases with increasing altitude of $1000 \mathrm{~m}$. The average LST of Inner City Zones, Outer City Zone and Forest Zone were calculated. Average altitudes of these three separate zones were derived from SRTM DEM. Then, corrected average LST values on the basis of lapse rate of changing average altitude were derived. Average calculated values of LST of Outer City Zone and Forest Zone were deduced on the basis of average altitude increased on the basis of lowest altitude zone (Inner City Zone). Thus, new average land surface temperatures of same altitude of three different zones were derived which validated the calculated LST derived from thermal image. Calculated LST from thermal image has been defined as actual mean and adjusted LST on the basis of lapse rate has been defined as corrected mean of LST.

\section{UHI calculation}

For evaluating UHI impacts on the urban quality of life, several thermal comfort indices are available (Zhang, 2006). This study adopted Urban Thermal Field Variance Index (UTFVI) which has been used in several past studies in the world. The UTFVI values are classified into five categories, each having corresponding interpreted ecological valuations and the UHI phenomenon (Liu and Zhang, 2011). The thermal environment in urban areas is characterized by HI phenomenon also called UHI/UFTVI which is used to quantitatively describe urban heat island effect. It is calculated by the formula:

$\mathrm{UFTVI}=\left(\mathrm{T}_{\mathrm{s}}-\mathrm{T}_{\text {mean }}\right) / \mathrm{T}_{\mathrm{s}}$

Where,

UFTVI is Urban Field Temperature Variance Index.

$\mathrm{T}_{\mathrm{s}}$ is actual land surface temperature

$\mathrm{T}_{\text {mean }}$ is mean value of land surface temperature

From the ecological evaluation, five ecological conditions can be identified like worse, bad, normal, good and excellent on the basis of UHI values (Table 2). 
Table 2: Interpretation of ecological condition based on UTFVI and UHI hierarchy

\begin{tabular}{|c|c|c|}
\hline UTFVI & UHI phenomenon & Ecological evaluation index \\
\hline More than 0.3 & Strongest & Worse \\
\hline From 0.2 to 0.3 & Strong & Bad \\
\hline From 0.1 to 0.2 & Middle & Gormal \\
\hline From 0 to 0.1 & Weak & Excellent \\
\hline Less than 0 & None & \\
\hline
\end{tabular}

\section{Results and discussions}

The situation of land use/ land cover in the year 1999 and 2017 and their changes were analyzed. Pattern and area changes of three land use/land cover zones were analyzed with its driving factors. Distribution patterns of LST in both years were analyzed separately with their determining factors. The relation between land use/ land cover and LST were analyzed with the help of derived value and field observation. Calculated LST were corrected on the basis of lapse rate of Nepal (Kattel et al., 2012). Local level variation of LST was also analyzed. Ecological conditions of three zones were analyzed on the basis of UTFVI values which indicate the level of extremities of UHI creation. Finally, evaluation was done to identify how much extremities of UHI have emerged due to the urbanization in Kathmandu valley.

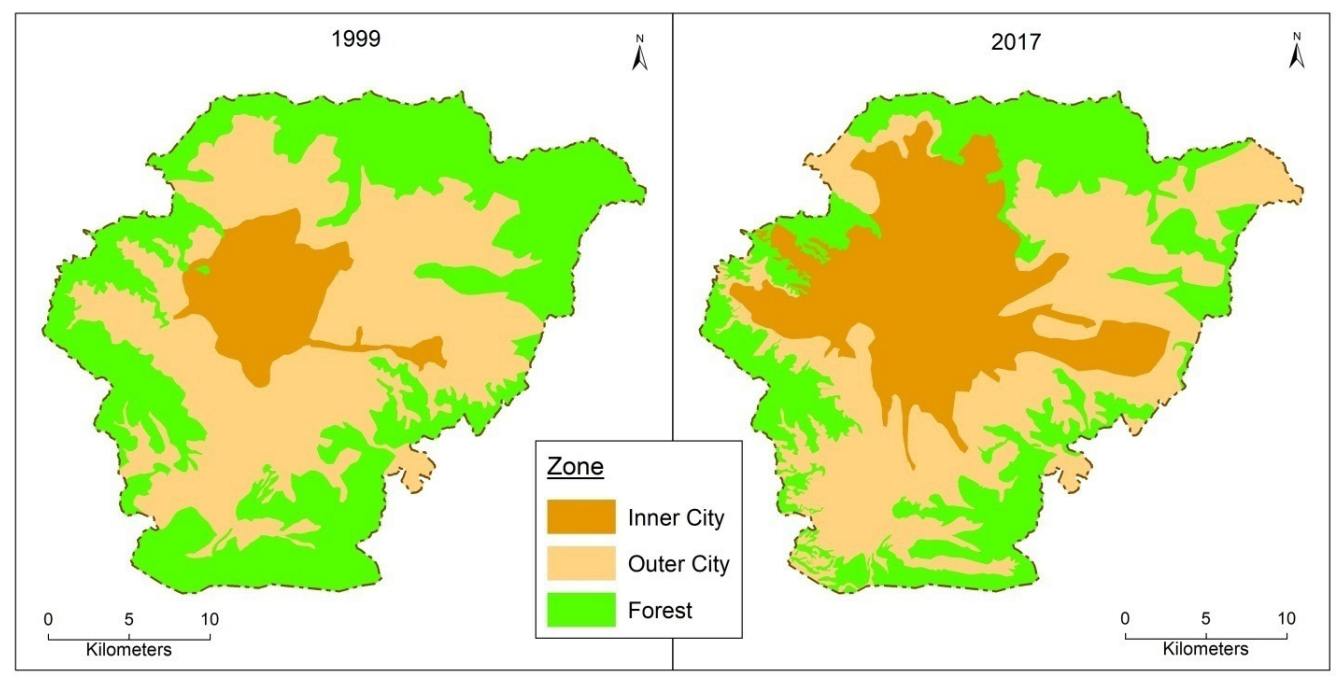

Figure 3: Land use/land cover in Kathmandu valley 
Area of Inner City Zone was only $10 \%$ of the total area of the valley in 1999 but it reached $36 \%$ of the total in 2017 while Outer City Zone became $45.25 \%$ to only $21 \%$ during same period. Area of Forest Zone slightly decreased. The Inner-City Zone increased more than three and half times during 1999 to 2017 which is nearly similar rate of population growth of 1981 to 2011. The Outer City Zone decreased more than $50 \%$ and forest also slightly decreased more than 3\% even in the steeply sloping hill sides. These data indicate the rapid urban expansion increasing the area of Inner City Zone encroaching Outer City Zone and Forest Zone decreased to the encroachment of Outer City Zone.

Table 3: Land use and land cover in 1999 and 2017

\begin{tabular}{|c|c|c|c|c|c|}
\hline \multirow{2}{*}{ Land use/ land cover } & \multicolumn{2}{|c|}{1999} & \multicolumn{2}{|c|}{2017} & \multirow{2}{*}{$\begin{array}{c}\text { Change } \\
(\%)\end{array}$} \\
\hline & Area km² & $\%$ & Area km ${ }^{2}$ & $\%$ & \\
\hline Inner City & 70.87 & $10 \%$ & 254.02 & $36 \%$ & 158.43 \\
\hline Outer City & 326.13 & $45.25 \%$ & 152.67 & $21 \%$ & -53.19 \\
\hline Forest & 319.92 & $44.75 \%$ & 310.23 & $43 \%$ & -3.03 \\
\hline
\end{tabular}

\section{Land surface temperature (LST)}

The spatial pattern of LST in Kathmandu valley shows that the central part of the valley has the higher value. Higher value is because of the presence of compact built-up surface such as buildings, roads and other concrete area while the vegetation areas are directly related to lower value of LST which is responsible for generating the cooling effect in the urban micro climate. Some concrete built-up areas add to the existing high temperature even in the outer parts of the valley. However, in some small part of the land, the LST has reached maximum $35.60^{\circ} \mathrm{c}$ due to the presence of concrete and brick industries. The concrete areas in Kathmandu district are more than in Lalitpur and Bhaktapur districts. The increment of LST outside the city core in 2017 is because of the expansion of urban built up area encroachment to Outer-City Zone. 


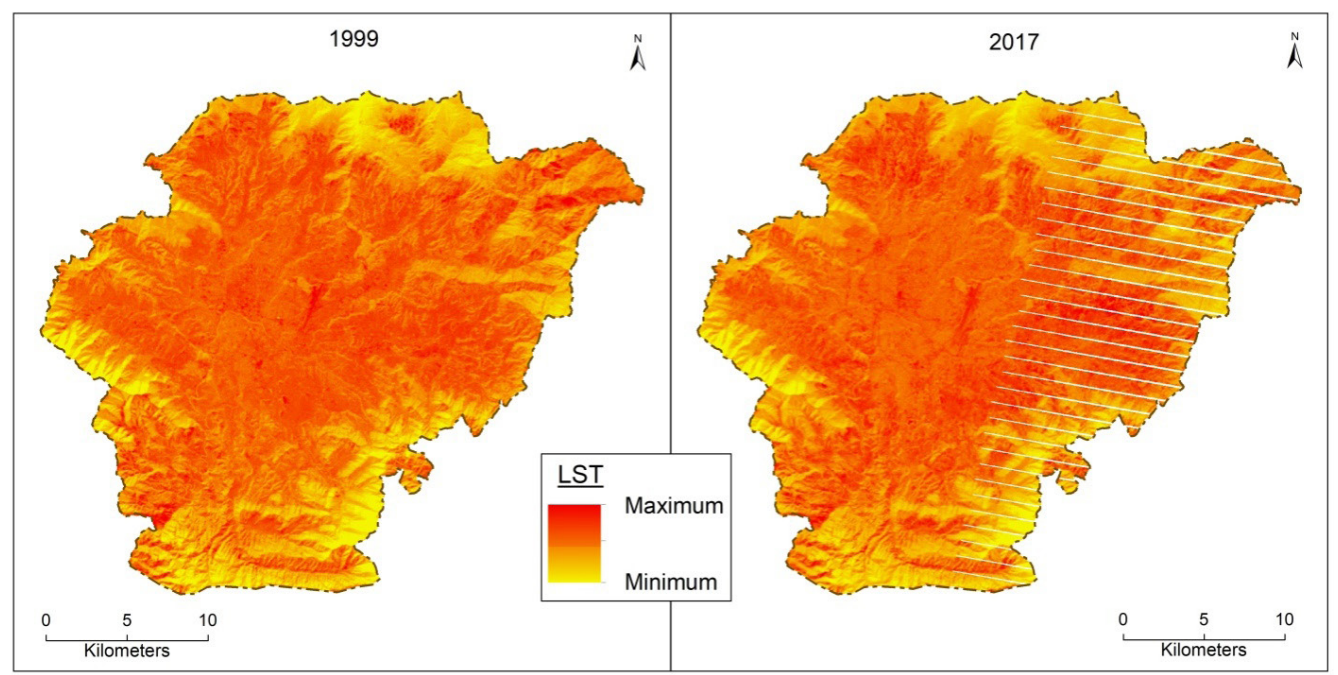

Figure 4: Distribution of LST in 1999 and 2017

The average LST values of Inner and Outer City Zones in 1999 were similar while maximum and minimum range was quite high. The range of Outer City Zone and Forest zone were similar. The range of Forest and Outer City Zone were quite high because of the altitudinal variation and variation of land use/land cover. Standard deviation also indicates the higher variation on LST in these two zones as compared to Inner City. However, the average LST was the highest in Inner City Zone and the lowest in the Forest Zone which indicates the creation of heat island in the urban one (Table 4). Corrected mean in the Outer City zone and Forest Zone is higher as compared to actual mean by which it can be expected that to have lower temperature in comparison to calculated values of LST in the Inner City Zones. This is the clear indication of creation of urban heat in Kathmandu valley due to urbanization.

The average LST values of Inner and Outer City Zones in 1999 were similar while maximum and minimum range was quite high. The range of Outer City Zone and Forest Zone were similar. The range of Forest and Outer City Zones were quite high because of the altitudinal variation and variation of land use/land cover. Standard deviation also indicates the higher variation on LST in these two zones as compared to Inner City Zone. However, the average LST was the highest in Inner City Zone and the lowest in the Forest Zone which indicates the creation of heat island in the urban one (Table 4). Corrected mean in the Outer City zone and Forest Zone is higher as compared to actual 
mean by which it can be expected that to have lower LST as compared to calculated values of LST in Inner City Zones. This is the clear indication of creation of urban heat in Kathmandu valley due to urbanization in 1999.

Table 4: Land surface temperature $\left({ }^{\circ} \mathrm{C}\right)$ in 1999

\begin{tabular}{|c|r|r|r|r|}
\hline LST & \multicolumn{1}{|c|}{ Forest } & \multicolumn{1}{|c|}{ Outer city } & \multicolumn{1}{|c|}{ Inner city } & \multicolumn{1}{c|}{ Valley total } \\
\hline Minimum & 8.7 & 12.9 & 16.4 & 8.7 \\
\hline Maximum & 34.1 & 38.5 & 34.2 & 38.5 \\
\hline Range & 25.4 & 25.6 & 17.8 & 29.8 \\
\hline Actual mean & 18.6 & 23.7 & 24.5 & 23.52 \\
\hline Corrected mean & 21.9 & 24.1 & 24.5 & 23.52 \\
\hline STD DEV & 2.89 & 1.60 & 1.23 & 2.86 \\
\hline
\end{tabular}

The highest value of LST was in the Inner City Zone followed by Outer City Zone in which the lowest value was in the Forest Zone in 2017. The ranges and standard deviation indicate the lower heterogeneity of land use/land cover in the Inner City Zone as compared to Outer City and Forest Zones. Standard deviation indicated the higher proportion of diversity in land cover in the Outer City zone as compared to the Forest zone. Both corrected and actual mean values of LST increased in all three zones in 2017 as compared to 1999 (Table 5). It indicates the effect of urbanization but further validation is needed to clarify it. However, the increasing area and average value of LST in 2017 as compared to 1999 further validated increasing LST in Kathmandu valley.

Table 5: Land surface temperature $\left({ }^{\circ} \mathrm{C}\right)$ of Kathmandu valley 2017

\begin{tabular}{|c|r|r|r|r|}
\hline LST & \multicolumn{1}{|c|}{ Forest } & Outer city & Inner city & Whole study area \\
\hline Minimum & 11.2 & 13.6 & 18.2 & 11.2 \\
\hline Maximum & 35.6 & 35.6 & 32.2 & 35.6 \\
\hline Actual mean & 21.3 & 25.1 & 25.6 & 22.10 \\
\hline Corrected mean & 23.1 & 25.2 & 25.6 & 22.10 \\
\hline Range & 24.4 & 22.0 & 14.0 & 24.4 \\
\hline STD DEV & 2.61 & 2.69 & 1.53 & 3.47 \\
\hline
\end{tabular}




\section{Urban heat island (UHI) and ecological condition}

Distribution patterns of UHI values in both years were similar but the intensity of the highest value extended to Outer City Zone in 2017 as compared in 1999. The higher values of UHI were increasing in the Inner City and Outer City Zones. Higher increase of intensity was extended more in Bhaktapur area. It indicated the extension of UHI outside of Inner City Zone. The highest value of UHI at the airport was similar in both years (Figure 5).

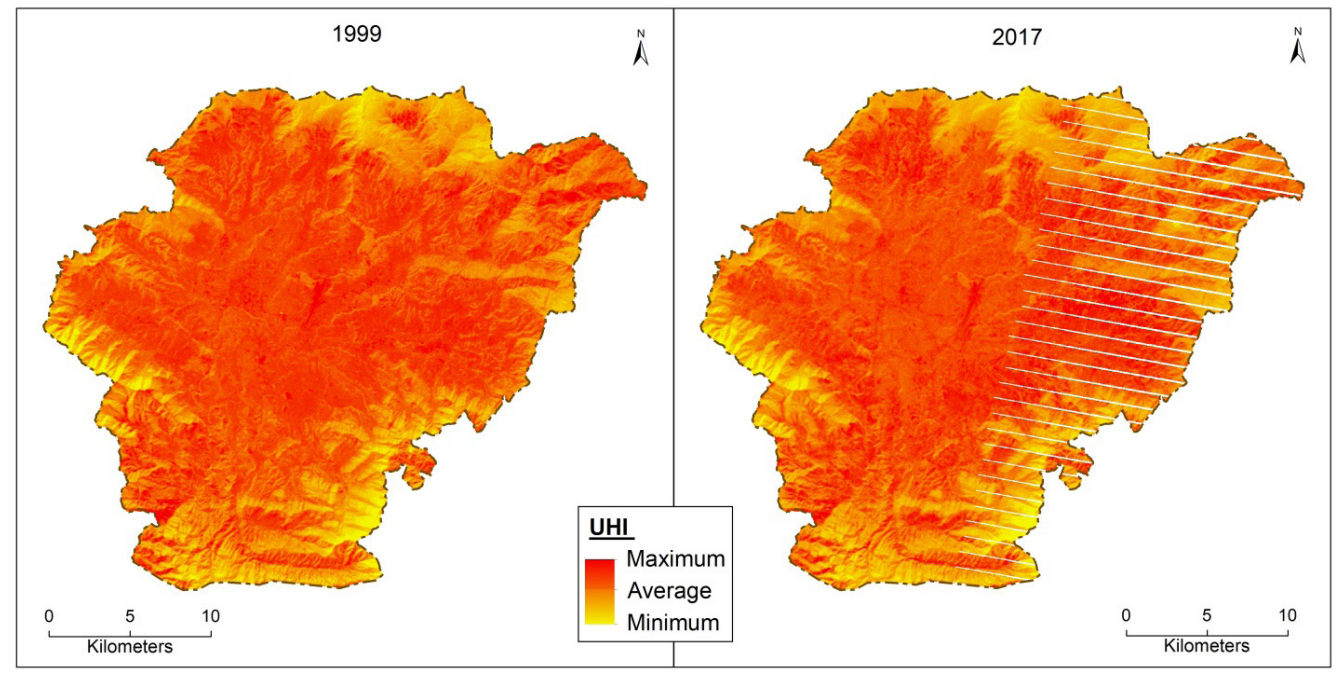

Figure 5: Distribution pattern of UHI index values

Only two ecological conditions were identified in Kathmandu valley. The vegetation area reflected the excellent ecological condition and built up surface reflects the good ecological condition. The distribution pattern of average ecological condition in both years was similar but higher proportion of the area was covered by excellent ecological condition in 2017 as compared in 1999. It was because of the extension of Inner City Zone toward the outer part in 2017 (Figure 6).

The higher proportion of excellent ecological condition was in outer parts in both years but higher proportion of excellent ecological condition was in 2017 as compared in 1999. It was because of the extension of this Outer City Zone to the vegetated area and high-altitude areas. Some parts were covered more vegetated area than built up surface in 2017. There was the highest intensity of excellent ecological conditions in the northeast, southwest and northeast parts in 2017 (Figure 6 and 7). It was because of the higher proportion of forest coverage and open spaces. 


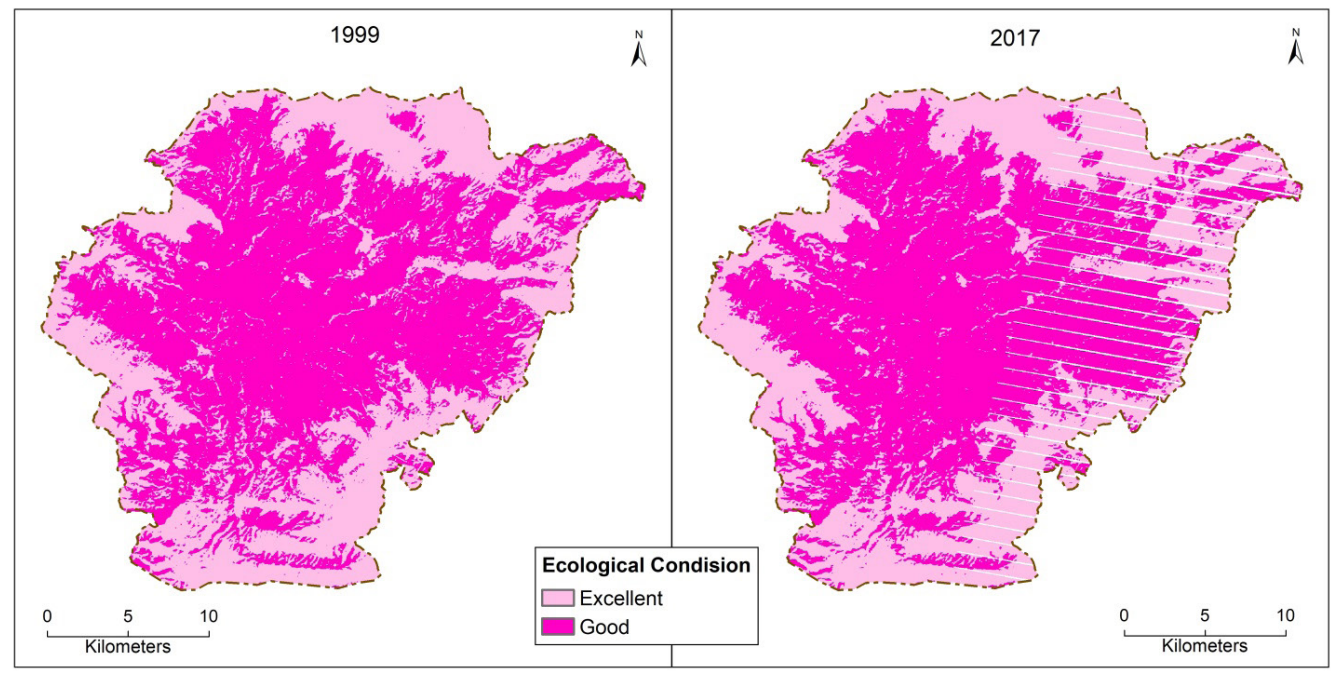

Figure 6: Distribution pattern of ecological condition in Kathmandu valley

Most of the Forest Zone was covered with the forest in both 1999 and 2017. Therefore, most of the areas had excellent ecological condition in 2017 because of the lower parts of Forest zone of 1999 was converted into Outer City Zone in 2017. Furthermore, Forest Zone in 2017 was mostly steep hill slope with high altitude region in which most of the forest in 1999 remained constant even in 2017. Thus, the average proportion of excellent ecological condition was more in 2017 as compared in 1999 (Figure 7) because of the conversion of Forest zone to Outer City Zone rather than actual land cover change.

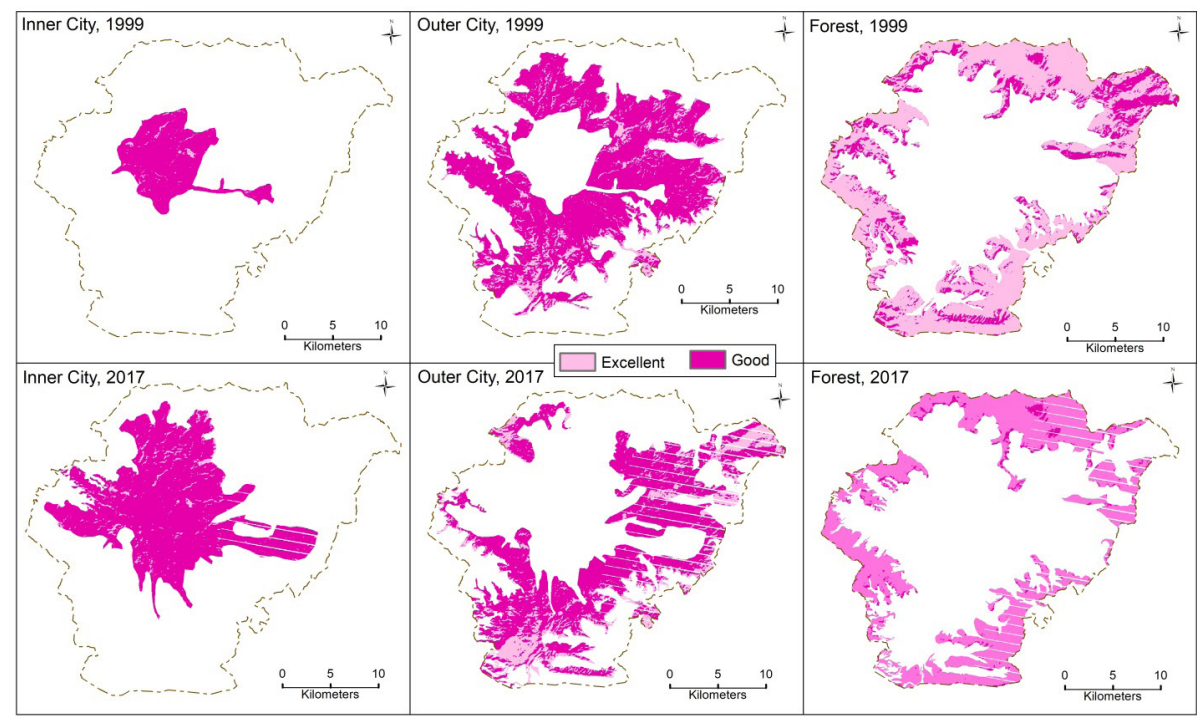

Figure 7: Distribution pattern of ecological condition in different zones 
The area proportion of excellent ecological condition in the Inner City Zone was very low in both years but proportion had slightly increased in 2017 because of the extension of area of Inner City Zone outside the city core and more open spaces in the extended area in 2017. The area of good ecological condition slightly decreased. However, the proportion of good ecological condition was the dominant in Inner City Zone. The area proportion of good ecological condition was decreasing toward Outer City Zone and Forest zones and excellent ecological condition was increasing (Table 6).

Table 6: Area percentage of ecological condition by zones

\begin{tabular}{|c|r|r|r|r|r|c|}
\hline \multirow{2}{*}{$\begin{array}{l}\text { Ecological } \\
\text { condition }\end{array}$} & \multicolumn{3}{|c|}{1999} & \multicolumn{3}{c|}{2017} \\
\cline { 2 - 7 } & Inner city & Outer city & Forest & Inner city & Outer city & \multicolumn{1}{c|}{ Forest } \\
\hline Excellent & 3.3 & 15.79 & 75.95 & 4.4 & 26.3 & 94.8 \\
\hline Good & 96.7 & 84.21 & 24.05 & 95.6 & 73.7 & 5.2 \\
\hline Total & 100.0 & 100.0 & 100.0 & 100.0 & 100.0 & 100.0 \\
\hline
\end{tabular}

Due to high rate of urbanization in Kathmandu valley, there is high rate of increase in the number of vehicles and brick factories resulting air pollution on the one hand, increasing proportion of the alphas and concrete road, high buildings, less greenery and less movement of air is on the other. These factors directly affected to the land surface temperature of the valley. The Inner-City Zone of Kathmandu valley is more likely to heat stress than the surrounding areas. Studies have revealed that the land surface temperature in the world is increasing due to global warming. Mountainous country like Nepal is highly affected by global warming especially in highland areas (Chaudhary and Aryal, 2009). The rate increment of LST in per decade in Nepal is quite lower than that of our finding of LST of 1999 and 2017. The data of this study is one time in a single year and it might have been affected by various factors to compare the temporal change in LST of Kathmandu valley during this period. Land surface temperature is varying with land use/land cover. The land surface temperature of urban built up area contains strong micro scale pattern that are relative to land categories like street, vertical walls, roofs, trees and albedo (Roth et al., 1989). Thus, the local variability of land surface temperature of Shivapuri to Dhapasi is highly variable due to the presence of forest, built-up area, agriculture land and open space area. Similar variability was also found in the airport area having variability of LST. Forest area had lowest LST value and runway of airport has the highest LST value. Other factors such as emission of air heating agents, air traffic and other infrastructure may also affected in increasing land surface temperature in the airport area which need further verification. This study 
also found the high value of LST in the brick industry areas. Neighboring houses and buildings also presented high value of LST. But this may be due to the use of number of air cooler machines which help to increase the temperature. So, the land use/land cover play vital role to increase land surface temperature. But there are so many causes to affect the LST. These are the subject matter for the further studies. Proportion of land surface temperature is increasing from 1999 to 2017 in all areas. The altitude of a land has also prominent role to affect the land surface temperature. Even after the correction of land surface temperature on the basis of seasonal variation of lapse rate of Nepal, land surface temperature of inner city is more than outer city and the forest areas. It revealed that land surface temperature in the urban area is really higher as compared to surrounding area of outer city and the forest in Kathmandu valley.

UHI effect has multiple implications to living condition of human life. UHI condition of Kathmandu Valley is not so bad but the increasing trend shows that it is going to be increase further in the future. Increasing UHIE can have adverse health effects occurring by significantly increasing air temperatures above average values, impeding the body's ability to adapt and stay cool (Forkes, 2010). Thus, regular monitoring of land surface temperature is required for better health of the people of increasing urban area of Kathmandu Valley.

\section{Conclusion}

Rapid urbanization in Kathmandu valley contributed increasing land surface temperature during 1999 to 2017. Increasing road, vehicles, built up surfaces, and decreasing open surfaces such as cultivated land, forest and opens spaces were the major factors of increasing land surface temperature. According to the analysis of thermal pattern of the study area, the temperature of inner city is more than outer city, and the temperature of outer city is more than the forest. It is evident that higher the urbanization more increment of temperature and high UHI effect. Interpretation of index quantitative evaluating of ecological effects was excellent and good in Kathmandu valley. However, the UHI indicated that increasing built up surface and other urban activities have an effect on increasing temperature in city area rather than newly un-urbanized part. Thus, in the future the ecological condition may be worse if this situation remain the same. Unplanned urbanization and lack of sufficient open spaces at present indicated the critical future in Kathmandu valley which may take long time to manage the residential and urbanization area to overcome the urban growth and UHI effect. 


\section{References}

Adinna, E., Christian, E. I. and Okolie, A. T. (2009). Assessment of urban heat island and possible adaptations in Enugu urban using landsat-ETM. Journal of Geography and Regional Planning, 2 (2): 030-036.

Alfraihat, R., Mulugeta, G. and Gala, T. S. (2016). Ecological evaluation of urban heat island in Chicago City, USA. Journal of Atmospheric Pollution, 4 (1): 23-29. doi:10.12691/jap-4-1 -3.

Artis, D.A. and, Carnahan, W.H.(1982). Survey of emissivity variability in thermography of urban areas. Remote Sensing and Environment, 12: 313-329.

Carlson, T. and Ripley, D. A. (1997). On the relation between NDVI, fractional vegetation cover, and leaf area index. Remote Sensing of Environment, 62 (3):241-252. doi: 10.1016/S0034-4257(97)00104-1

Chaudhary, P. and Aryal, K. (2009). Global warming in Nepal: Challenges and policy imperatives. Journal of Forest and Livelihood, 8 (1): 4-14.

Das, A. (2015). Estimation of land surface temperature and its relation to land cover land use: A case study on Bankura District, West Bengal, India.

DHM (2015). Study of climate and climatic variation over Nepal. Kathmandu: Department of Hydrology and Meteorology (DHM), Government of Nepal.

Forkes, J. (2010). Urban heat island mitigation in Canadian communities. Toronto: Clean Air Partnership.

Gao, Z., Hou, Y. and Chen, W. (2019). Enhanced sensitivity of the urban heat island effect to summer temperatures induced by urban expansion. Environment Research Letters, 14094005.

Grover, A. and Singh, R. B. (2015). Analysis of urban heat island (UHI) in relation to normalized difference vegetation index (NDVI): A comparative study of Delhi and Mumbai. Environments, 2: 125-138. doi: 10.3390/environments2020125. 
Dipendra Salami, Ramesh Kumar, Chhabi Lal / Assessment of urban ...Vol. 14: 1-20, 2021

Grimmond, S. (2007). Urbanization and global environmental change: Local effects of urban warming. The Geographical Journal. https://doi.org/10.1111/j.14754959.2007.232_3.x

Ishtiaque, A., Shrestha, M. and Chhetri, N. (2017). Rapid urban growth in the Kathmandu Valley, Nepal: Monitoring land use land cover dynamics of a Himalayan city with Landsat imageries. Environments, 4, 72.doi:10.3390/environments4040072.

Jeevalakshmi, D., Reddy, S. N. and Manikiam, B. (2017). Land surface temperature retrieval from LANDSAT data using emissivity estimation. International Journal of Applied Engineering Research, 12 (20):9679-9687.

Kattel, D. B., Yao, T., Yang, K., Tian, L., Yang, G.,andJoswiak, D. (2013). Temperature lapse rate in complex mountain terrain on the southern slope of the Central Himalayas. Theoretical and Applied Climatology, 113:671-682. doi: 10.1007/ s00704-012-0816-6.

Leeson, G. W. (2018). The growth, ageing and urbanisation of our world. Population Ageing, 11: 107-115. https://doi.org/10.1007/s12062-018-9225-7

Liang, S.; Li, X. and Wang, J. (2012). Advanced remote sensing: Terrestrial information extraction and applications. Elsevier Science: Amsterdam, Netherlands.

Lillesand, T. M., Kiefer R. W. and Chipman, J. W. (2011). Remote sensing and image interpretation (6 ${ }^{\text {th }}$ Edition). New Delhi: John Wiley and Sons, Inc.

Liu, L. and Zhang, Y. (2011).Urban heat island analysis using the Landsat TM data and ASTER Data: A case study in Hong Kong. Remote Sensing, 3 (12):1535-1552. doi: $10.3390 /$ rs3071535.

Li, Y., Schubert, S., Kropp, J. P. and Rybski, D. (2020). Urban canopy parameterization data for urban climate simulation using CCLM/DCEP and hourly $2 \mathrm{~m}$ temperature output. PANGAEA. https://doi.org/10.1594/PANGAEA.914906

Lo, C. P. and Quattrochi, D. (2003). Land-use and land-cover change, urban heat island phenomenon, and health Implications: A remote sensing approach. 
Photogrammetric Engineering and Remote Sensing, 69 (9):1053-1063. doi: 10.14358/PERS.69.9.1053.

Nuruzzaman, M. (2015). Urban heat island: Causes, effects and mitigation measures - A review. International Journal of Environmental Monitoring and Analysis, 3(2): 67-73.

Roth, M., Oke, T. R., \& Emery, W. J. (1989).Satellite-derived urban heat island from three coastal cities and the utilization of such data in urban climatology. International Journal of Remote Sensing, 10: 1699-1720

S. S.; V, A. S. and K, M. (2016), Estimation of land surface temperature of high range mountain landscape of Devikulam Taluk using Landsat 8 data. International Journal of Research in Engineering and Technology, 4 (1): 92-96. doi:10.1016/j. agrformet.2008.06.001

Stewart, I. D. and Oke, T. R. (2012).Local climate zones for urban temperature studies. Bulletins of American Meteorological Society (BAMS), 93 (12): 1879-1900.doi. org/10.1175/BAMS-D-11-00019.1.

Subedi, B. P. (2014). Urbanization in Nepal: Spatial pattern, social demography and development. Population Monograph of Nepal, III: 95-154. Kathmandu: Central Bureau of Statistics (CBS), Government of Nepal.

Suresh, S., Ajay S. V. and Mani, K. (2016).Estimation of land surface temperature of high range mountain landscape of Devikulam Taluk using Landsat 8 data. International Journal of Research in Engineering and Technology, 5(1): 92-96.

United Nations (2014). World urbanization prospects: 2014 revision. New York: Department of Economic and Social Affairs, Population Division,

USGS (2015), Landsat 8 (L8) Data Users Handbook, LSDS 1574, Version 1.Sioux Falls: Department of the Interior, U.S. Geological Survey.

Wienert, U. and Kuttler, W. (2005). The dependence of the urban heat island intensity on latitude - A statistical approach. Meteorologische Zeitschrift, 14 (5): 677-686. doi: 10.1127/0941-2948/2005/0069. 
Dipendra Salami, Ramesh Kumar, Chhabi Lal / Assessment of urban ...Vol. 14: 1-20, 2021

Zhang, Y. (2006). Land surface temperature retrieval from CBERS-02 IRMSS thermal infrared data and its applications in quantitative analysis of urban heat island effect. Journal of Remote Sensing, 10: 789-797.

Zhang, Z. \& He, G. (2013).Generation of Landsat surface temperature product for China, 2000-2010.International Journal of Remote Sensing, 34, 7369-7375. 